\title{
EFFECT OF HOTZ PLATE APPLIANCE TO MAXILLARY ARCH DEVELOPMENT PATIENTS WITH CLEFT LIP AND PALATE
}

\author{
Edy Machmud \\ Department of Prosthetic Dentistry Faculty of Dentistry University of Hasanuddin,
}

\begin{abstract}
The purpose of this study was to analyze the effect of hotz plate appliance to maxillary arch development of complete unilateral cleft lip and palate patient. The subjects were divided into two groups." The first group consisted of 6 patients, aged under two years with hotz appliance, recruited from Hasan Sadikin Hospital Bandung, and the second group, as control group, consisted of 6 patients, aged under two years, without hotz appliance, recruited from Haji Hospital Makassar. It was showed that in group with hotz plate appliance, no difference found on the size of anterior maxillary arch and minor maxillary arch. On the other hand, in the control group, minor maxillary arch was longer than mayor maxillary arch. It was concluded that hotz plate appliances affected the palatal development of patient with complete unilateral cleft lip and palate. Indonesian Journal of Dentistry 2006. Edisi Khusus KPPIKG XIV:4/2-415
\end{abstract}

Key words: cleft lip and palate, hotz plate appliance

\section{Introduction}

Manifestation of cleft lip and palate of newborn exhibits a difference face morphology pattern compared with those without cleft lip and palate. This congenital defect cause face asymmetry and deviation of growth pattern from face structure.' A characteristic of complete unilateral cleft lip and palate of patients is a separation of lip, alveolar, and palate structure to two portions. The portion with defect is known as side of cleft and other portion known as side without cleft. Side without cleft is characterized with more shifting of major maxillary arch away from cleft together with shifting of nose and nasal septum. This shifting caused minimal bone support to persist muscle attraction, and attached of lip muscle at the wrong place is on nose bases ${ }^{2}$.

There are so many techniques and methods of application hotz plate appliances that developed since 1960 untill now, combined with bone graft. Some investigators disagree with application of this appliance, but another investigator gives a support of successfully treatment with hotz plate appliance. ${ }^{3}$

They, who were contrary with application of this stated that effects of surgical lip improve can cause modeling action of maxillary arch naturally, match and close each other. They stated that major and minor maxillary arch can move and close each other without hotz plate appliance. ${ }^{4,5}$

These contradictions can solve with research on centre treatment of cleft lip and palate patient. According to the problem, this study investigates the effect of hotz plate appliances to maxillary arch development babies with clecft lip and palate.

\section{Objectives}

To analyze major and minor maxillary arch length of complete unilateral cleft lip and palate of patients, who use hotz plate appliance, compared with them without using the appliance. Another purpose of this study was first, to analyze the anterior minor maxillary arch length of complete unilateral cleft lip and palate patient which apply 
hotz plate appliance compared with them without that appliance. Secondly, was to analyze minor maxillary arch length and major maxillary arch length of complete unilateral cleft lip and palate of patient, who apply hotz plate appliance compared with them without that appliance. Lastly, to analyze minor maxillary arch length and major maxillary arch length without applying hotz plate appliance.

\section{Materials and Method}

\section{Materials}

1. Hydrophilic vinyl polysiloxane impression material (Exaflex)

2. Individual custom tray for children

3. Measurement appliance is Mitutoyo Caliper's from Japan with $0,02 \mathrm{~mm}$ of level of accuracy.

\section{Methods}

Maxillary studies were performed with certained point of landmark as a reference point to analyze maxilla. Method of measurement is based on Otto kriens method's. ${ }^{6}$

Maxillary reference point model.

A-C: Anterior Region Major Arch Length

Major maxillary arch length linear is placed on cleft side, measured from canines cusp in the major maxillary arch to interdentally central incisor.

A-C': Anterior Region Minor Arch length

Minor maxillary arch length linear place on cleft side, measured from canine cusp in minor arch to interdentally central incisor.

S-S': Anterior wide

Anterior cleft length linear, measured from tip of major alveolar arch and tip of minor alveolar arch.

\section{C-C'}

Canine point on canine cusp, if there is no canine, we can use frentum labialis lateral and top of ridge alveolar of intersection point.

TT'

Point of tuberosity or point of intersection of maxillary and top of ridge alveolar posterior.

Working cast was taken from jaw casting of complete unilateral cleft lip and palate patient in surgical room, immediately before performing palate coverage surgical. Impression material that use to working cast from those patients is an hydrophilic vinyl polysiloxane impression material (Exaflex) with high accuracy, ideally flow rate and viscosities and hard quickly. The result of the impression was cast with hard gypsum as a working cast. Measurement of linear length was performed once using Mitutoyo Caliper's Japan with 0,02 level of accuracy. The measurement of working cast is pointed to major and minor maxillary arch length stake at reference point from pentagonal feature, $\mathrm{A}$ as a point of top. C-C' as a roof of building and T-T as bases of building. AC linear length measurement represents anterior portion major segment and minor measurement is $\mathrm{AC}^{\prime}$ measure (cleft side) that AS, SS' and S'C'. According normal jaw study model that have pentagonal building and $\mathrm{TT}^{\prime}$ as a base of building. For easier, anterior portion (non cleft side) is calted non cleft $\mathrm{AC}$ and portion anterior minor arch (cleft side) is called cleft $A C{ }^{6}$

\section{Result}

Mean value of major maxillary arch length of application hotz plate appliance, showed in Table 1 . Statistical result indicated that there is no significantly differences $(p<0.05)$ between major maxillary arch length patient with hotz plate appliance and major maxillary arch length patient without an appliance.

Mean value of minor maxillary arch length of application hotz plate appliance, showed in Table 2 . Statistical result indicated that there is significantly difference $(\mathrm{p}<0.05)$ between minor maxillary arch length of application hotz plate appliance and without application an appliance.

Mean value of minor maxillary arch length and major maxillary arch length of application hotz plate appliance, showed in Table 3. Statistical result indicated that there is no significantly difference $(p<0.05)$ between minor maxillary arch length and major maxillary arch length application botz plate appliance.

Mean value minor maxillary arch length and major maxilary arch length, showed in Table 4. Statistical result indicated that there is significantly difference $(p<0.05)$ between length of minor maxillary arch and length of major maxillary arch without application hotz plate appliance.

\section{Discussion}

Description of anterior maxillary arch length form by the measurement of major and minor maxillary arch length to the patients with and without hotz plate appliance, is the one way to see the effect of the use hotz plate appliance to the cleft lip and palate patients. Some studies related to hotz plate appliance, are two dimensional measurement of a maxillary cast model ${ }^{3}$, and linear curve 
measurement by the trigonometric measurement technique, which measure a palate surface angle and maxillary arch length radius circle. ${ }^{7}$

The most valid measurement is the three dimensional technique, which was developed to analyze maxillary palate and arch length configuration to the cleft lip and palate patients. Three dimensional analyze is used with longitudinal manner with a serial cast model of the cleft lip and palate patients with age range from 3,6 month and the next ege. These expected describe a palate development more accurately including a palate configuration of cleft lip and palate patients with hotz plate appliance. The effectiveness of the use hotz plate appliance by winters, beside to see the major and minor maxillary arch length, it is used to see the presence of cross bite and the direct of incicivus lateral development. ${ }^{8,9}$

The result showed that there is a difference of minor arch length between patients with and without an appliance. Compared with the patients using hotz plate appliance, the minor maxillary arch length of without hotz plate appliance is significantly difference which minor maxillary arch length of the patients with an appliances $(15,252 \pm 1,614 \mathrm{~mm})$.

The minor maxillary arch length of the cleft lip and palate patients without hotz plate appliance has a different size with major maxillary arch length $(19,010 \pm 3,605 \mathrm{~mm})$.

An observation to minor maxillary arch shown position, arch curvature, and cleft distance to the major maxillary arch, caused a significant differences that minor maxillary arch length was more length than major maxillary arch length.

The measurement of major maxillary arch length in this study, both to the patient with or without hotz plate appliance, shown that there was no significantly differences. Major maxillary arch of the cleft lip and palate patients, was a past of maxillary structural that had no abnormality or had no cleft. Thus, major maxillary arch represented maxillary structural that had no developmental abnormalities. In fact that study measurement result was there no differences of major maxillary arch length size between the patients with or without an appliance. This was according to Honda and Mishima studies, that used anterior maxillary arch length size to the age group when the cleft palate reconstruction was taken place. In fact, this study was no differences of palatal anteroposterior size, both in patients with or without hotz plate appliance. $^{10,11}$
This study was compared the cleft lip and palate patient with and without hotz plate appliance, and found that there was a significant differences of the length of minor maxillary arch for both group. The length if minor maxillary arch without hotz plate appliance $(19,010 \pm 3,605 \mathrm{~mm})$ was different with the length of minor maxillary arch with hotz plate appliance $(15,252 \pm 1,614 \mathrm{~mm})$.

The patients with hotz plate appliance, had no difference between minor maxillary arch and major maxillary arch, because of an appliance influenced the minor maxillary arch slided and approached the major maxillary arch, thus it had been repositioned and matched, symmetry and had a some length.

Mishima studied the effectiveness of Hotz plate in children with cleft lip and palate until they had a labioplasty surgery. His study was compare with cleft lip and palate without Hotz plate as a control.

The result showed that the patients with Hotz plate leaded to prevent a maxillary segmental slide to lateral, against to the attractive force of orbicularis oris muscles. Without Hotz plate, maxillary segmental slide to laterally and anteriorly. This was according to Mishima, between Hotz plate group and without Hotz plate group in the 18 month group, with cleft size of minor maxillary arch and major maxillary arch of Hotz plate user, more smaller than patient without Hotz. In the principle, that using of Hotz plate leaded to prevent a maxillary segmental slides to laterally, against the attractive force if orbicularis oris muscle and able to narrowing the size of cleft."

Hotz plate has a significant role to prevent the segment slide laterally and collapse caused by the force of orbicularis oris muscle after labioplasty. The cleft lip and palate patient with this devices leaded to prevent the maxillary segment collapse to medially caused of the force of lip muscle and that influence. Still remains until the age of 4 year Huddart studied the patients with cleft lip and plate with hotz plate appliance before surgery. This devices act as feeding aid decrease the size of the cleft wide and creates the lip muscles more relax especially when the cleft lip reconstruction was taken place. Although Ross was not agreed with this statement, but he considered that hotz plate appliance that used to baby was not show the longitudinal effect to face development. ${ }^{3.5}$. It shown that major maxillary arch and minor getting closed. The use of hotz plate to the infants with cleft lip and palate is combined with external elastic strapping. The use of a wire as anchorage to extra oral and 
adjacent to the infants cheek, prevent that devices swallow.

In the longitudinal study of the patients with cleft lip and palate at one side, found that developmental potential was more faster in minor arch than the major arch to the two year first birth, the development was faster in minor maxillary arch. ${ }^{8}$ Pruzansky saw that the phenomenon of development growth of palate both in hard and soft tissues had a developmental level that more faster and had ability to achieve the developmental process after the reconstruction. $^{12}$

Although there was an interval time and he delayed of developmental process. After surgery, the development will delay. The delayed maxillary growth was temporer after the surgery, but will accelerated to achieve a normal arch.

\section{Conclusion}

From this research we concluded that application of hotz plate appliance before surgery had an effect to the anterior minor maxillary arch symmetry. Whereas on the patients without an appliance, anterior minor maxillary arch was not symmetrical and collapsed into the anterolateral and anteromedial direction.

Table 1. Major maxillary arch length patient with hotz plate appliance and patient without an appliance

\begin{tabular}{cccc}
\hline \multirow{2}{*}{ Variable } & \multicolumn{2}{c}{$\begin{array}{c}\text { Mean } \pm \text { Standard deviation } \\
\text { (mm) }\end{array}$} & $\begin{array}{c}\text { Significance } \\
(\mathrm{p}<0.05)\end{array}$ \\
\cline { 2 - 3 } & $\begin{array}{c}\text { With hotz } \\
\text { plate }\end{array}$ & $\begin{array}{c}\text { Without } \\
\text { appliance }\end{array}$ & 0,313 \\
\hline Major & $16.293 \pm$ & $16.776 \pm$ \\
Maxillary & 1.8479 & 0,759 & \\
Arch & & & \\
\hline Note : $T_{\text {count }}=1.024 ;$ & $T_{\text {tatle }}=1: 70 ;$ Non significance
\end{tabular}

Table 2. Minor maxillary arch length of application hotz plate appliance and without application an appliance

\begin{tabular}{|c|c|c|c|}
\hline \multirow[t]{2}{*}{ Variable } & \multicolumn{2}{|c|}{$\begin{array}{c}\text { Mean } \pm \text { Standard deviation } \\
(\mathrm{mm})\end{array}$} & \multirow{2}{*}{$\begin{array}{l}\text { Significance } \\
\left(p^{2}<0.05\right)\end{array}$} \\
\hline & $\begin{array}{c}\text { With hotz } \\
\text { plate }\end{array}$ & $\begin{array}{l}\text { Without } \\
\text { appliance }\end{array}$ & \\
\hline $\begin{array}{c}\text { Minor } \\
\text { Maxillary } \\
\text { Arch } \\
\end{array}$ & $\begin{array}{l}15.252 \pm \\
1.614\end{array}$ & $\begin{array}{l}19.010 \pm \\
3.605\end{array}$ & $0.000^{* * 7}$ \\
\hline $\begin{array}{l}\text { Note: } T_{\text {cour }} \\
\text { significanc }\end{array}$ & $\overline{4.037}$ & 1.70 & More \\
\hline
\end{tabular}

Table 3. Minor maxillary arch length and major maxillary arch length of application hot $z$ plate appliance.

\begin{tabular}{|c|c|c|c|}
\hline \multirow{2}{*}{ Subject } & \multicolumn{2}{|c|}{$\begin{array}{l}\text { Mean } \pm \text { Standard deviation } \\
(\mathrm{mm})\end{array}$} & \multirow{2}{*}{$\begin{array}{c}\text { Significance } \\
(p<0.05)\end{array}$} \\
\hline & $\begin{array}{c}\text { Major } \\
\text { maxillary } \\
\text { arch }\end{array}$ & $\begin{array}{l}\text { Minor } \\
\text { maxillary } \\
\text { arch }\end{array}$ & \\
\hline $\begin{array}{l}\text { Aplication } \\
\text { hotz plate } \\
\text { appliance }\end{array}$ & $\begin{array}{c}16.293 \pm \\
1.848\end{array}$ & $\begin{array}{c}15.252 \pm \\
1.614\end{array}$ & $0.078^{\text {s. }}$ \\
\hline
\end{tabular}

Table 4. Minor maxillary arch length and major maxillary arch length without application hotz plate appliance.

\begin{tabular}{cccc}
\hline \multirow{2}{*}{ Subject } & \multicolumn{2}{c}{$\begin{array}{c}\text { Mean } \pm \text { Standard deviation } \\
(\mathrm{mm})\end{array}$} & $\begin{array}{c}\text { Significance } \\
(\mathrm{p}<0.05)\end{array}$ \\
\cline { 2 - 3 } & $\begin{array}{c}\text { Major } \\
\text { maxillary } \\
\text { arch }\end{array}$ & $\begin{array}{c}\text { Minor } \\
\text { maxillary } \\
\text { arch }\end{array}$ & \\
\hline Without & $16.776 \pm$ & $19.010 \pm$ & $0.026^{* 7}$ \\
Application & 0.759 & 3.605 & \\
hotz plate & & \\
Appliance & & \\
\hline Note: $\mathrm{T}_{\text {count }}=1.442 ; \quad \mathrm{T}_{\text {1able }}=1.74 ; * *$ Significant
\end{tabular}

\section{References}

1. Dah1 E. Craniofacial Morphology in Congenital Cleft Lip and Palate. An X-ray Cepalometric Study of Young Adult Males. Acta Odontol Scan J 1970; 28: suppi 57.

2. Mazaheri $M$, Athannasiou $A E$, Long $R E$, Kolokitha $O G$. Evaluation of Maxillary Dental Arch form in Unilateral Cleft Lip and Palate from One Month to Four Years Cleft Palate. Craniofacial J 1993; 30: 90-3.

3. Huddart AG. Presurgical Orthopedic Treatment in Children with Unilateral Cleft Palate. J Cleft Palate 1979; 20 : 897. 904.

4. Skoog T. The Use of Periosteal Flap in the Repair of Clefts Primary Palate. $J$ Cleff Palate 1965: 2: 332-9.

5. Ross RB. Treatment Variable Affecting Facial Growth in Complete Unilateral Cleft Lip and Palate. Part 7 : An overview of treatment and facial growth Cleft Palate $J$ 1977; 24:71-6.

6. Kriens O. Anatomy of the Cleft Palate Primary Surgical Treatment of Cleft Palate.WB. Saunders Co.1974.

7. Prasad. Quantitative 3D maxillary arch evaluation of two different infant-managements for unilateral cleft lip and palate. J Cleft Palate Craniofac. 999: 7:562-70.

8. Berkowitz S. Stereophotogrammetric Analysis of Cast of Normal and Abnormal Palate. Philadelphia: WB. Saunders Co. 1985

9. Winters JC. Prcsurgical Orhopedic in the Surgical Management of Unilateral Cleft Lip and Palate. Plastic Reconstr. Surg I 1995: 95: 755-64.

10. Honda Y, Suzuki A. Longitudinal Study on the Changes of Maxillary Asch Dimention in Japanese Children with Cleft Lip or Palate. Cleft Palate Craniofac J 1994. 32:2.

11. Mishima K, Mori Y, Sugahara T. Comparison between Palatal Configurations in UCLP lnfants with and without a Hotz Plate until four Years of Age. Cleft Palate Craniofac.J 1999; 37: 185-90.

12. Pruzansky S. Factors Determining Arch form in Clefts of Lip and Palate. Am J Orthod 1955;41:827-52. 